\title{
Effect of withdrawal of fusafungine from the market on prescribing of antibiotics and other alternative treatments in Germany: a pharmacovigilance impact study
}

\author{
Karin Hedenmalm ${ }^{1,2}$ (D) Xavier Kurz ${ }^{3} \cdot$ Daniel Morales $^{3}$
}

Received: 3 October 2018 / Accepted: 15 February 2019 / Published online: 5 March 2019

(C) The Author(s) 2019

\begin{abstract}
Purpose Knowledge on unintended consequences of product withdrawals is limited. Fusafungine, indicated for treatment of upper respiratory airways disease (URAD), was withdrawn in the EU on May 28, 2016. Given concerns about possible substitution with antibiotics, this study aimed to assess the impact of the withdrawal of fusafungine on prescribing of antibiotics and other treatments.

Methods The study was conducted using data from general practitioner (GP) and ear, nose and throat (ENT) practices in IMS® Disease Analyzer Germany. The quarterly prevalence of fusafungine prescribing was analysed for consultations involving the most common URAD between May 29, 2013 and May 28, 2017 in regular fusafungine-prescribing practices. Trends in the quarterly prevalence of antibiotics (AB), other nasal or throat preparations (N\&T) and tyrothricin were analyzed. Practices with no fusafungine prescribing during the study served as controls. Changes in prescribing trend were evaluated using interrupted time series regression analysis.

Results In fusafungine-prescribing practices, withdrawal of fusafungine was associated with an immediate increase in prescribing of other N\&Ts among patients consulting for URAD $(+6.4 \%, 95 \%$ CI $2.3-10.5 \%$ in GP practices and $+9.0 \%$, 95\% CI 5.5$12.5 \%$ in ENT practices). There was no increase in antibiotic prescribing. In ENT practices; a small transient increase in tyrothricin prescribing occurred. No changes were seen in non-fusafungine-prescribing practices.

Conclusions Withdrawal of fusafungine was not associated with increased prescribing of antibiotics but was associated with increased prescribing of other N\&Ts. The unintended impact of substitution to other treatments should be considered routinely when products are withdrawn or restricted in other ways.
\end{abstract}

Keywords Fusafungine $\cdot$ Upper respiratory airways disease $\cdot$ Antibiotics $\cdot$ Alternative prescribing

Electronic supplementary material The online version of this article (https://doi.org/10.1007/s00228-019-02650-z) contains supplementary material, which is available to authorized users.

Karin Hedenmalm

karin.hedenmalm@ema.europa.eu

1 Business, Data and Analytics Department, European Medicines Agency, 30 Churchill Pl, Canary Wharf, London E14 5EU, UK

2 Department of Laboratory Medicine, Karolinska Institutet, Solna, Stockholm, Sweden

3 Pharmacovigilance and Epidemiology Department, European Medicines Agency, London, UK

\section{Introduction}

Fusafungine is an antimicrobial and anti-inflammatory agent administered via inhalation into the nostrils or orally. It was authorised in 19 European Union (EU) member states for local antibacterial and anti-inflammatory treatment of upper respiratory airways disease (URAD), including sinusitis, rhinitis, rhinopharyngitis, angina, laryngitis and tracheitis [1]. Fusafungine consists of a mixture of enniatins [2] and has been widely used over the past 50 years [1]. Its first authorisation in the EU was in 1963. Fusafungine has multiple mechanisms of action, including downregulation of the expression of intercellular adhesion molecule-1 (ICAM-1) and inhibition of production of proinflammatory cytokines [3]. In September 2015, an EU-wide assessment of the benefit-risk of fusafungine was initiated due to an increase in the reporting 
rate of serious allergic reactions [4], estimated at a rate of 0.17 cases per 100,000 canisters [1]. In February 2016, the European Medicines Agency (EMA) Pharmacovigilance Risk Assessment Committee (PRAC) recommended that fusafungine should be withdrawn from the EU market, and this recommendation was implemented with immediate effect on 28 May $2016[5,6]$. In addition to the risk of serious allergic reactions, contributing factors to the withdrawal decision included the lack of evidence around efficacy/ effectiveness and the inability to exclude the risk of antimicrobial resistance $[1,6]$.

Medicinal products are removed from the market due to unfavorable benefit-risk profiles. However, these decisions might lead to substitutions to alternative medicines that are not always necessary, safer or more effective. The aim of this study was to estimate the impact of the market withdrawal of fusafungine in Germany on potential alternative treatments including antibiotics, locally acting antimicrobials and other nasal or throat preparations for the management of URAD.

\section{Methods}

\section{Data source}

Germany was selected for the study due to a high rate of prescriptions for fusafungine [7], whereas in some other EU countries (e.g. France and the United Kingdom) fusafungine was not available on the market. The study used data from the IMS® Disease Analyzer Germany, version June 2017. IMS $®$ Disease Analyzer Germany contains anonymised medical records from a representative panel of general practitioners (GPs), specialists in internal medicine and other specialist physicians in computerized practices throughout Germany since 1992 [8]. Primary care data from Germany contains data on diagnoses, prescriptions, and risk factors such as smoking or obesity, referrals and sick notes and test results. In Germany, patients are not required to register with a GP to be referred to a specialist physician.

\section{Study design}

A time series study design was used to measure the impact of fusafungine withdrawal among patients seeking consultation for URAD. The study observation period was from 29 May 2013 to 28 May 2017. Practices included in the study were required to have continuous data delivery between May 2013 and June 2017. The study included data from GPs and ear, nose and throat (ENT) specialists capturing $98.6 \%$ of all fusafungine prescriptions.

\section{Indication for treatment}

Consultations for the most commonly occurring URAD conditions were defined by screening and ranking clinical diagnoses recorded on the same day as fusafungine in order of frequency. The three most common diagnoses that were selected and included for GP practices were acute pharyngitis (ICD code J02.9), acute upper airways infection (ICD code J06.9) and acute laryngitis (ICD code J04.0), and for ENT practices, they were acute laryngitis (ICD code J04.0), acute pharyngitis (ICD code J02.9) and acute laryngopharyngitis (ICD code J06.0).

\section{Fusafungine-prescribing practices}

Trends in prescribing were compared between regular fusafungine-prescribing practices and non-fusafungineprescribing practices. Regular fusafungine-prescribing practices were defined as practices having at least $0.5 \%$ of all patients prescribed fusafungine, and at least $5 \%$ of patients consulting for URAD, in each year for 3 years prior to the withdrawal of fusafungine. GP and ENT practices with no fusafungine prescribing in the same period were then selected as a control group.

\section{Exposures}

Four types of exposure were analyzed: prescriptions for fusafungine-containing products, prescriptions for systemic antibiotics, prescriptions for other locally acting antimicrobials besides fusafungine, i.e. tyrothricin-containing products and prescriptions for other nasal or throat preparations (N\&Ts). Fusafungine- and tyrothricin-containing products were identified by substance name belonging to the EphMRA ATC code R01A4 (nasal anti-infectives without corticosteroids) and R02A0 (throat preparations) respectively. Other N\&Ts were identified by EphMRA ATC codes: R01A topical nasal preparations, R01B systemic nasal preparations and $\mathrm{R} 02 \mathrm{~A}$ throat preparations, excluding products containing fusafungine or tyrothricin. Systemic antibiotics were identified by the following EphMRA ATC codes: J01A tetracyclines and combinations, J01B chloramphenicol and combinations, J01C broad-spectrum penicillins, J01D cephalosporins, J01E trimethoprim and similar preparations, J01F macrolides and similar types, $\mathrm{J} 01 \mathrm{G}$ fluoroquinolones, $\mathrm{J} 01 \mathrm{H}$ plain medium and narrow spectrum penicillins and penicillin/ streptomycin combinations, J01K aminoglycosides, J01L carbenicillin and similar types, J01P other beta-lactam antibacterials excluding penicillins and cephalosporins and J01X other antibacterials. 


\section{Analysis}

Among patients consulting for URAD, trends in the following treatments were examined over the study period using quarterly time intervals: (1) treatment with systemic antibiotics, (2) treatment with fusafungine, (3) treatment with tyrothricin, (4) treatment with other N\&T, and (5) no treatment. The treatments were defined as mutually exclusive groups. Quarterly time intervals were defined from 29 May to 28 August, 29 August to 28 November, 29 November to 28 February and 29 February/1 March to 28 May for each year. Interrupted time series regression analysis was chosen to statistically evaluate the effect of the withdrawal [9]. Using linear regression analysis, the immediate impact of the withdrawal and any change in subsequent trends in prescribing was compared between the 12 pre-intervention quarters and the 4 post-intervention quarters [10]. Autocorrelation was evaluated using the Durbin Watson test [11-13]. Analysis was conducted using SAS Enterprise Guide version 7.13. All analyses were performed by the authors based on IMS® Disease Analyzer Germany.

\section{Results}

A total of $31 \mathrm{GP}(3.0 \%)$ and 17 ENT (15.5\%) regular fusafungine-prescribing practices were identified, within which 4644 GP patients (3.8\%) and 7527 ENT patients (3.4\%) were prescribed fusafungine during the study period. Of these patients, $64.2 \%$ of GP patients and $64.6 \%$ of ENT patients had a concomitant diagnosis of URAD identified. In GP practices, the most common URAD diagnosis was upper airways infection, followed by acute pharyngitis, acute laryngitis and acute laryngopharyngitis. In ENT practices, the most common URADs were acute pharyngitis, acute laryngitis, acute laryngopharyngitis and upper airways infection. The distribution of diagnoses was similar in regular fusafungineprescribing practices compared to non-fusafungineprescribing practices (Supplementary material, Table A1).

\section{Prescribing trends in URAD}

\section{Regular fusafungine-prescribing GP and ENT practices}

Trends in the quarterly prevalence of prescribing of each treatment for URAD are shown in Fig. 1. for both regular fusafungine-prescribing practices and non-fusafungineprescribing control practices. Among regular fusafungineprescribing GP practices, the quarterly prevalence of fusafungine prescribing immediately fell in the quarter following the date of withdrawal (immediate change $-7.8 \%, 95 \% \mathrm{CI}$ -11.8 to $-3.7 \%$ ) (Table 1). Among regular fusafungineprescribing ENT practices, the quarterly prevalence of fusafungine prescribing also immediately fell in the quarter following the date of withdrawal (immediate change $13.7 \%, 95 \% \mathrm{CI}-17.3$ to $-10.1 \%$ ).

Among regular fusafungine-prescribing GP practices, the quarterly prevalence of other N\&T prescribing immediately rose in the quarter following the date of withdrawal (immediate change $6.4 \%, 95 \%$ CI 2.3 to $10.5 \%$ ) with no significant change in trend compared to the pre-intervention trend. Among regular fusafungine-prescribing ENT practices, the quarterly prevalence of other N\&T prescribing also immediately rose in the quarter following the date of withdrawal (immediate change $9.0 \%, 95 \%$ CI 5.5 to $12.5 \%$ ) with no significant change in trend compared to the pre-intervention trend.

Fusafungine withdrawal was associated with a small significant immediate increase in tyrothricin prescribing in regular fusafungine-prescribing ENT practices only (immediate change $1.7 \%, 95 \%$ CI 1.3 to $2.2 \%$ ), with a significant decrease in trend compared to the pre-intervention trend $(-0.3 \%, 95 \%$ $\mathrm{CI}-0.5$ to $-0.2 \%)$. In both GP and ENT regular fusafungineprescribing practices, there was no significant immediate increase or change in trend in systemic antibiotic prescribing associated with fusafungine withdrawal.

\section{Non-fusafungine-prescribing control practices}

Fusafungine withdrawal was not associated with any significant changes in prescribing of systemic antibiotics, tyrothricin or other N\&T in non-fusafungine-prescribing GP or ENT control practices.

\section{Discussion}

Electronic health records provide an important means to study the impact of medicines regulatory interventions on prescribing behaviour. Our study found that in regular fusafungine prescribing GP and ENT practices in Germany, the withdrawal of fusafungine was associated with an immediate change in health care professional behaviour with increased prescribing of other N\&T products for URAD. In this regard, there was no significant change in the proportion of untreated patients, an effect similarly noted in other interventions resulting in changing antibacterial guideline recommendations [14]. Importantly, we observed no statistically significant increase in prescribing of systemic antibiotics and only a small temporary increase in prescribing of tyrothrocin-containing products from ENT practices, which is reassuring in terms of the risk of antibiotic resistance and other antibiotic-related adverse drug reactions that may have occurred. In this regard, a decreased prescribing of systemic antibiotics due to treatment with fusafungine has been reported in France [15, 16], and consequently an increase in prescribing of systemic antibiotics after withdrawal of fusafungine may have been expected. 

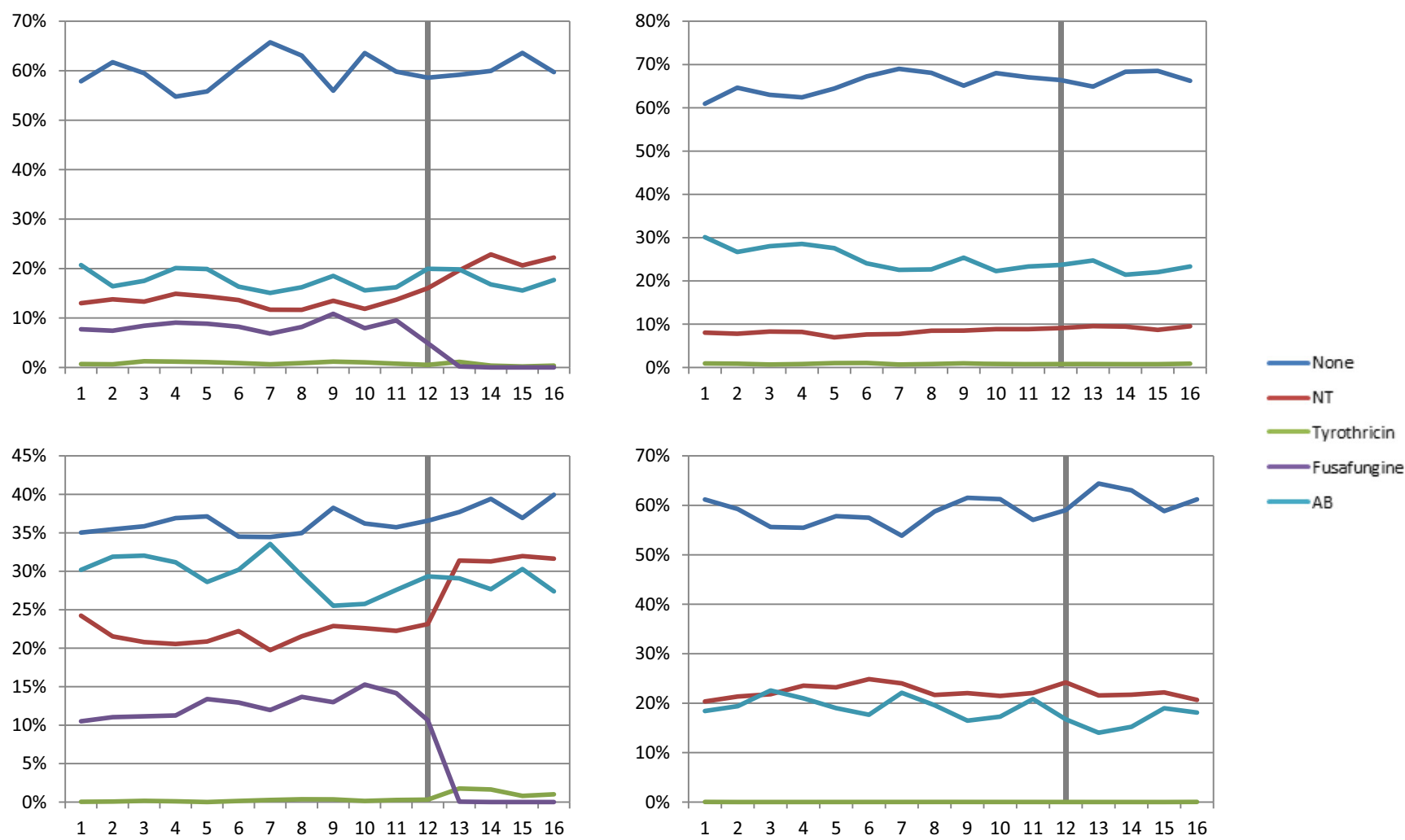

Fig. 1 a-d Quarterly prevalence of treatment prescribing for consultations with an upper respiratory airways disease (URAD) in general practitioner (GP) and ear, nose and throat practices (ENT) in Germany. a Fusafungine-prescribing GP practices (top left). b GP control practices not prescribing fusafungine (top right). c Fusafungineprescribing ENT practices (bottom left). d ENT control practices not prescribing fusafungine (bottom right). Horizontal axis, quarterly time periods between 29 May 2013 and 28 May 2017 starting from quarter 1 (3 years before the withdrawal of fusafungine) to quarter 16 ( 1 year after the withdrawal of fusafungine), Vertical axis, percent of consultation days for a selected diagnosis that concerned the specified treatment pathway.

The most common other N\&Ts in fusafungine-prescribing practices during the study period included mometasone (21.6\%), xylometazoline (14.2\%), xylometazoline in combination with dexpanthenol (10.1\%) and multisubstance preparations $(9.7 \%)$. These substances may carry their own risks, for example xylometazoline could cause sympathomimetic adverse reactions [17-20], and mometasone could cause adrenal suppression if significant systemic absorption occurs when used in high doses over long periods of time [21-23]. Long-term use of nasal decongestants such as xylometazoline is also associated with a risk of development of rhinitis medicamentosa [24]. Hence, it is unknown to what extent the discontinuation of fusafungine and subsequent change in health care professional behaviour with increased prescribing of other N\&Ts has actually resulted in an improved overall net-benefit risk balance for patients.

Although the findings are reassuring, our study suggests that it is important to follow up on the consequences of regulatory interventions leading to the withdrawal of medicinal

The dark grey bar indicates the last quarter when fusafungine could still be prescribed. Treatment pathways: None, no treatment; NT, treatment with other nasal and throat preparations (not containing fusafungine and tyrothricin) alone; Tyrothricin, treatment with tyrothricin but no treatment with systemic antibiotics or fusafungine; Fusafungine, treatment with fusafungine but no treatment with systemic antibiotics, and $\mathrm{AB}$, treatment with systemic antibiotics. URAD: acute pharyngitis (ICD code J02.9), acute laryngitis (ICD code J04.0), acute laryngopharyngitis (ICD code J06.0) or upper airways infection (ICD code J06.9). Own calculations, based on IMS® Disease Analyzer Germany

products from the market and to ascertain the extent to which substitution by alternative treatments occur, particularly in cases where alternative treatment options may themselves confer other risks. The effects of other measures of drug restrictions, not limited to regulatory actions, could also be studied using the same methods. In this regard, a recent systematic review of studies measuring the impact of regulatory interventions found that examining unintended consequences of regulatory decisions, such as substitutions and spill-over effects, was infrequently performed after implementation of regulatory actions [25].

This study has some potential limitations. Firstly, the interrupted time series regression approach only examines temporal associations which may be influenced by other factors if occurring during the same time. However, the absence of an effect within the control practices (nonfusafungine prescribing) provides further evidence that the observed effects are indeed related to the withdrawal 
Table 1 Interrupted time series analysis of changes in prescribing of alternative treatments for upper respiratory airways disease (URAD) after withdrawal of fusafungine. Significant changes $(p<0.05)$ are shown in italic. $A B$ treatment with systemic antibiotics, $C L$ confidence limits, $E N T$ ear, nose and throat, GP general practitioner, Fusafungine treatment with fusafungine but not systemic antibiotics, Other $N \& T$ treatment with other nasal and throat preparations not containing fusafungine or tyrothricin alone, Tyrothricin treatment with tyrothricin but not fusafungine or systemic antibiotics, URAD acute pharyngitis (ICD code J02.9), acute laryngitis (ICD code J04.0), acute laryngopharyngitis (ICD code J06.0) or upper airways infection (ICD code J06.9). Own calculations, based on IMS® Disease Analyzer Germany

\begin{tabular}{|c|c|c|c|c|c|}
\hline \multirow[t]{2}{*}{ Type of practice } & \multirow[t]{2}{*}{ Alternative treatment } & \multicolumn{2}{|l|}{$\begin{array}{l}\text { Immediate change in prescribing } \\
\text { in percent }(95 \% \mathrm{CL}) \\
\text { after withdrawal of fusafungine }\end{array}$} & \multicolumn{2}{|c|}{$\begin{array}{l}\text { Change in trend in prescribing } \\
\text { in percent ( } 95 \% \text { CL) after } \\
\text { withdrawal of fusafungine }\end{array}$} \\
\hline & & $\begin{array}{l}\text { Fusafungine-prescribing } \\
\text { practices }^{1}\end{array}$ & Control practices ${ }^{2}$ & $\begin{array}{l}\text { Fusafungine-prescribing } \\
\text { practices }^{1}\end{array}$ & Control practices $^{2}$ \\
\hline \multirow[t]{5}{*}{ GP } & No treatment & $-1.5 \%(-11.2 \%: 8.2 \%)$ & $-2.4 \%(-7.8 \%: 3.1 \%)$ & $0.3 \%(-3.0 \%: 3.6 \%)$ & $0.0 \%(-1.9 \%: 1.8 \%)$ \\
\hline & Other N\&T & $6.4 \%(2.3 \%: 10.5 \%)$ & $0.7 \%(-0.7 \%: 2.1 \%)$ & $0.5 \%(-0.9 \%: 1.9 \%)$ & $-0.2 \%(-0.7 \%: 0.3 \%)$ \\
\hline & Tyrothricin & $0.3 \%(-0.5 \%: 1.1 \%)$ & $-0.0 \%(-0.4 \%: 0.3 \%)$ & $-0.2 \%(-0.5 \%: 0.0 \%)$ & $0.0 \%(-0.0 \%: 0.1 \%)$ \\
\hline & Fusafungine & $-7.8 \%(-11.8 \%:-3.7 \%)$ & NA & $-0.0 \%(-1.4 \%: 1.4 \%)$ & NA \\
\hline & $\mathrm{AB}$ & $2.5 \%(-3.3 \%: 8.4 \%)$ & $1.7 \%(-3.1 \%: 6.6 \%)$ & $-0.6 \%(-2.6 \%: 1.4 \%)$ & $0.2 \%(-1.4 \%: 1.9 \%)$ \\
\hline \multirow[t]{5}{*}{ ENT } & No treatment & $1.1 \%(-2.6 \%: 4.7 \%)$ & $6.6 \%(-0.6 \%: 13.8 \%)$ & $0.3 \%(-0.9 \%: 1.6 \%)$ & $-1.5 \%(-3.9 \%: 1.0 \%)$ \\
\hline & Other N\&T & $9.0 \%(5.5 \%: 12.5 \%)$ & $-1.1 \%(-4.8 \%: 2.7 \%)$ & $0.1 \%(-1.1 \%: 1.3 \%)$ & $-0.3 \%(-1.6 \%: 0.9 \%)$ \\
\hline & Tyrothricin & $1.7 \%(1.3 \%: 2.2 \%)$ & $-0.0 \%(-0.1 \%: 0.0 \%)$ & $-0.3 \%(-0.5 \%:-0.2 \%)$ & $0.0 \%(-0.0 \%: 0.0 \%)$ \\
\hline & Fusafungine & $-13.7 \%(-17.3 \%:-10.1 \%)$ & NA & $-0.3 \%(-1.5 \%: 1.0 \%)$ & NA \\
\hline & $\mathrm{AB}$ & $1.8 \%(-4.1 \%: 7.7 \%)$ & $-5.5 \%(-11.1 \%: 0.0 \%)$ & $0.2 \%(-1.8 \%: 2.2 \%)$ & $1.8 \%(-0.1 \%: 3.7 \%)$ \\
\hline
\end{tabular}

\footnotetext{
${ }^{1}$ Practices with a minimum level of prescribing of fusafungine: $\geq 0.5 \%$ of all patients and $\geq 5 \%$ of patients with a selected diagnosis were prescribed fusafungine during each of the 3 years prior to the withdrawal of fusafungine (31 GP practices and 17 ENT practices)

${ }^{2}$ Practices with no prescribing of fusafungine during the 3 years prior to the withdrawal of fusafungine (291 GP practices and 17 ENT practices)
}

of fusafungine. Not all studies of the impact of regulatory interventions have used such robust methods for comparison [25].

Over the counter use of fusafungine as well as any in hospital prescribing of fusafungine were not captured in our study, which may limit the generalizability of our findings. We also selected exposed and unexposed practices to demonstrate the impact of the fusafungine withdrawal, and hence not all GP and ENT practices were included in our study. Furthermore, we only examined trends in prescribing for the most common consultations for URAD, the main indication for fusafungine prescribing, although trends for overall prescribing in practices with the highest levels of fusafungine prescribing (at least 5\% of all patients; 2 GP practices and 4 ENT practices) were also similar (data not shown).

In conclusion, the European Medicines Agency regulatory intervention leading to a withdrawal of fusafungine in the EU did not lead to substitute prescribing of systemic antibiotics whereas it did lead to a switch towards higher prescribing of other N\&T products in Germany. In light of concerns about excessive use of antibiotics that may lead to antibiotic resistance, these results are re-assuring. They also highlight the need to consider the impact of medicine withdrawals, and other regulatory interventions, on substitution to other treatments to avoid potential unintended consequences.

\section{Compliance with ethical standards}

Conflict of interest The authors declare that they have no conflict of interest.

Disclaimer The views expressed in this article are the personal views of the authors and may not be understood or quoted as being made on behalf of or reflecting the position of the European Medicines Agency or one of its committees or working parties.

Open Access This article is distributed under the terms of the Creative Commons Attribution 4.0 International License (http:// creativecommons.org/licenses/by/4.0/), which permits unrestricted use, distribution, and reproduction in any medium, provided you give appropriate credit to the original author(s) and the source, provide a link to the Creative Commons license, and indicate if changes were made.

Publisher's note Springer Nature remains neutral with regard to jurisdictional claims in published maps and institutional affiliations.

\section{References}

1. Pharmacovigilance Risk Assessment Committee (PRAC). Assessment report, referral under Article 31 of Directive 2001/83/ EC resulting from pharmacovigilance data. Fusafungine containing medicinal products for oromucosal and nasal use, Procedure number: EMEA/H/A-31/1420 London, United Kingdom2016 [Available from: http://www.ema.europa.eu/docs/en_GB/ 
document_library/Referrals_document/Fusafungine_31/Position provided by_CMDh/WC500204834.pdf. Accessed 1 June 2018

2. Sy-Cordero AA, Pearce CJ, Oberlies NH (2012) Revisiting the enniatins: a review of their isolation, biosynthesis, structure determination and biological activities. The Journal of Antibiotics 65(11):541-549

3. German-Fattal M (2001) Fusafungine, an antimicrobial with antiinflammatory properties in respiratory tract infections. Clinical Drug Investigation 21(9):653-670

4. Fusafungine containing medicinal products for oromucosal and nasal use London, United Kingdom: European Medicines Agency; 2015 [Available from: http://www.ema.europa.eu/ema/index.jsp? curl=pages/medicines/human/referrals/Fusafungine for oromucosal_and_nasal_use/human_referral_prac_000054. jsp\&mid=WC0b01ac05805c516f. Accessed 1 June 2018

5. European Medicines Agency (2016) Timetable for the implementation of the CMDh position. European Medicines Agency, London, United Kingdom

6. European Medicines Agency (2016) CMDh endorses revocation of authorisations for fusafungine sprays used to treat airway infections. Medicines to be withdrawn due to serious allergic reactions and limited evidence of benefit. [Available from: http://www.ema. europa.eu/docs/en_GB/document_library/Press_release/2016/03/ WC500203974.pdf. Accessed 1 June 2018

7. Nochmals LOCABIOSOL Häufig verwendet, immer überflüssig. Arznei-telegramm, Germany 1998 [Available from: https://www. arznei-telegramm.de/html/1998 03/9803035 03.html. Accessed 11 July 2018

8. Becher H, Kostev K, Schroder-Bernhardi D (2009) Validity and representativeness of the "disease analyzer" patient database for use in pharmacoepidemiological and pharmacoeconomic studies. Int J Clin Pharmacol Ther 47(10):617-626

9. Kontopantelis E, Doran T, Springate DA, Buchan I, Reeves D (2015) Regression based quasi-experimental approach when randomisation is not an option: interrupted time series analysis. BMJ: Br Med J 350:h2750

10. Wagner AK, Soumerai SB, Zhang F, Ross-Degnan D (2002) Segmented regression analysis of interrupted time series studies in medication use research. J Clin Pharm Ther 27(4):299-309

11. Durbin J, Watson GS (1950) Testing for serial correlation in least squares regression: I. Biometrika 37(3/4):409-428

12. Durbin J, Watson GS (1951) Testing for serial correlation in least squares regression. II. Biometrika 38(1/2):159-177
13. Durbin J, Watson GS (1971) Testing for serial correlation in least squares regression. III. Biometrika 58(1):1-19

14. Hernandez-Santiago V, Marwick CA, Patton A, Davey PG, Donnan PT, Guthrie B (2015) Time series analysis of the impact of an intervention in Tayside, Scotland to reduce primary care broadspectrum antimicrobial use. J Antimicrob Chemother 70(8):23972404

15. Fagnani F, German-Fattal M (2003) Antibiotic prescribing patterns of French GPs for upper respiratory tract infections: impact of fusafungine on rates of prescription of systemic antibiotics. Am J Resp Med : drugs, devices, and other interventions 2(6):491-498

16. Laccourreye O, Cauchois R, Landais P, German-Fattal M (2003) The impact of fusafungine on the prescription of antibiotics in the treatment of rhinopharyngitis. Presse Medicale (Paris, France : 1983) 32(13 Pt 1):615-619

17. Figueiras-Graillet LM, Martinez-Selles M, Perez-David E, Fernandez-Aviles F (2013) Reversible cardiomyopathy due to chronic use of xylometazoline topical nasal spray. Int J Cardiol 164(2):e17-e18

18. Buysschaert I, Van Dorpe J, Dujardin K (2011) Hypertensive crisis and end-organ damage induced by over-the-counter nasal decongestant abuse. Eur Heart J 32(24):3114

19. Leupold D, Wartenberg KE (2011) Xylometazoline abuse induced ischemic stroke in a young adult. Neurologist 17(1):41-43

20. Meldgaard K, Vesterby A, Ostergaard JR (1997) Sudden death due to rupture of a saccular intracranial aneurysm in a 13-year-old boy. Am J Forensic Med Pathol 18(4):342-344

21. Allen DB (2000) Systemic effects of intranasal steroids: an endocrinologist's perspective. J Allergy Clin Immunol 106(4 Suppl): S179-S190

22. Gill G, Swift A, Jones A, Strain D, Weston P (2001) Severe adrenal suppression by steroid nasal drops. J R Soc Med 94(7):350-351

23. Broersen LHA, Pereira AM, Jørgensen JOL, Dekkers OM (2015) Adrenal insufficiency in corticosteroids use: systematic review and meta-analysis. The Journal of Clinical Endocrinology \& Metabolism 100(6):2171-2180

24. Graf P (1997) Rhinitis medicamentosa: aspects of pathophysiology and treatment. Allergy 52(40 Suppl):28-34

25. Goedecke T, Morales DR, Pacurariu A, Kurz X (2018) Measuring the impact of medicines regulatory interventions - systematic review and methodological considerations. Br J Clin Pharmacol 84(3):419-433 